\title{
Global Public Health
}

\section{Requests for medication abortion support in Brazil during and after the Zika epidemic}

\section{Alexandra Wollum , Sara Larrea , Caitlin Gerdts \& Kinga Jelinska}

To cite this article: Alexandra Wollum , Sara Larrea , Caitlin Gerdts \& Kinga Jelinska (2020):

Requests for medication abortion support in Brazil during and after the Zika epidemic, Global Public Health, DOI: 10.1080/17441692.2020.1809694

To link to this article: https://doi.org/10.1080/17441692.2020.1809694

\section{Published online: 25 Aug 2020.}

Submit your article to this journal $₫$

Џll Article views: 16

Q View related articles ๘

View Crossmark data 


\title{
Requests for medication abortion support in Brazil during and after the Zika epidemic
}

\author{
Alexandra Wollum ${ }^{a}$, Sara Larrea ${ }^{b}$, Caitlin Gerdts ${ }^{a}$ and Kinga Jelinska ${ }^{b}$ \\ ${ }^{a}$ Ibis Reproductive Health, Oakland, USA; ${ }^{b}$ Women Help Women, Amsterdam, Netherlands
}

\begin{abstract}
Brazil declared a public health emergency during the Zika virus epidemic, recommending avoiding pregnancy. This study analyses requests received by Women Help Women for information about and support for selfmanaged medication abortion (MA) in Brazil during and after the Zika epidemic to understand how Zika may have impacted requests to the service. This analysis considered 20,609 requests for MA support received between January 2016 and June 2017. Reasons for seeking an abortion were analysed alongside geographic trends in the percent and rate of requests citing Zika as a reason for seeking abortion. The average number of daily requests for MA support increased from 31 in January 2016 to 48 in June 2017. The average percent of daily requests citing Zika as a reason for seeking an abortion decreased from 15\% in March 2016 to $1.5 \%$ by June 2017. The most common reason for abortion seeking during and after the Zika epidemic was not being prepared for a child or not wanting any or additional children (between $52 \%-59 \%$ of requests). As the Zika epidemic slowed, MA requests citing Zika as a reason decreased, while requests increased overall. Few people cited Zika alone as a reason for abortion seeking, necessitating a broad contextualisation of abortion access in people's daily lived experiences and realities.
\end{abstract}

\section{ARTICLE HISTORY}

Received 20 November 2019 Accepted 27 July 2020

\section{KEYWORDS}

Abortion; Zika; Brazil; Induced abortion; Selfmanaged abortion

\section{Introduction}

In November of 2015, Brazil declared a national public health emergency because of the sharp increase in microcephaly cases linked to the Zika virus (Governo do Brasil, 2015; Marinho et al., 2016) and the World Health Organization (WHO) declared a Public Health Emergency of International Concern (PHEIC) in February of 2016 (World Health Organization, 2016). During the Zika epidemic, some countries encouraged women to avoid pregnancy indefinitely given the link between the virus and microcephaly and other brain malformations. The Brazilian government stressed the importance of counselling and access to family planning (Ministério da Saúde, 2015).

It is estimated that, under normal circumstances, more than $50 \%$ of births in Brazil are unintended, resulting, in part, from unequal access to contraceptive services (Ministério da Saúde, 2009; Theme-Filha et al., 2016). In addition, abortion is severely restricted in Brazilian law, allowing for abortion only when a woman's life is endangered, in cases of rape, or if a fetus is ancephalic leaving few legal options for pregnancy termination. Despite these legal restrictions, it is estimated that approximately 500,000 abortions take place each year in Brazil (Diniz et al., 2017).

Zika emerged in the context of widespread economic and social inequity in Brazil, factors that also influence access to reproductive health services (Castro et al., 2018; Marteleto et al., 2017). In Brazil, 
those who are socioeconomically disadvantaged are more likely to live in areas with poor access to sanitation and in houses without screens, air conditioning, or insect repellent - increasing the likelihood of contact with mosquitoes ('70,3\% dos domicílios', 2013; Paradella, 2018). In 2016, municipalities with the lowest socioeconomic levels were concentrated in the Northeast of Brazil (Albuquerque et al., 2017). Literature suggests that the North and Northeast regions of Brazil, where Zika incidence was highest, have the highest unmet need for family planning and the lowest levels of contraceptive use (Farias et al., 2016; Tavares et al., 2007). Research has shown that lack of information about free public services may limit access to contraceptive services among those for whom cost is a barrier to access (Center for Reproductive Rights, 2018). In Brazil, previous research has also shown that access to safe abortion services varies by socioeconomic status and people who cannot pay for the high cost of an illegal abortion at a private clinic turn to other methods (Diniz \& Medeiros, 2010; Fusco, 2013; Fusco et al., 2016; Kane et al., 2013; Marteleto et al., 2017). In the wake of the Zika epidemic, there has been an increased awareness of many of these dynamics and efforts have been made to better monitor the demand and quality of services for contraceptive and abortion services in Zika-affected areas; however, these efforts focus almost exclusively on how Zika alone impacts the demand for services (Ali et al., 2017). Given the broader social and economic constraints faced by those at higher risk for Zika, it is important to contextualise the need for abortion services more broadly, among other reasons that people may have to seek an abortion.

Self-managed abortion using misoprostol is thought to be common in Brazil and self-managed medication abortion is increasingly recognised as a safe and acceptable option to terminate a pregnancy (Aiken et al., 2017; Diniz \& Medeiros, 2010; Foster et al., 2017; Gerdts et al., 2018; Gomperts et al., 2008; Gomperts et al., 2014; Grossman et al., 2018; Moseson et al., 2020; World Health Organization, 2007). Previous research has suggested that requests for self-managed medication abortion support increased significantly after national public health advisories were implemented in countries with autonomous transmission of the Zika virus, including Brazil (Aiken et al., 2016). This evidence comes from requests made to one specific website, Women on Web, which provides information and access to abortion medications through an international telemedicine service. Aiken et al. (2016), however, used only information on the total number of requests and did not parse apart the reasons for abortion-seeking, limiting the conclusions that can be drawn with these data. The current study aims to describe the requests received for medication abortion support by a different organisation with a similar service: Women Help Women. Women Help Women is an international organisation that provides access to abortion medication as well as email support during the self-managed abortion process to people in countries where abortion access is restricted. We use data collected by Women Help Women to describe trends in medication abortion during and after the Zika epidemic in Brazil. Our analysis has two aims (1) to characterise requests for medication abortion support related to Zika and (2) to understand how important concern about Zika was in the context of other reasons for seeking an abortion.

\section{Materials and methods}

\subsection{Data and measures}

In the process of requesting Women Help Women's service, people fill in an online form. The form collects data to determine the requester's eligibility for medication abortion (days since the last menstrual period, possible contraindications for the use of Mifepristone and Misoprostol, method of pregnancy confirmation), as well as some demographic information needed for the service logistics (birth date, address, and other personal data). In mid-February 2016, after the declaration of the public health emergency in Brazil, questions about the reasons for seeking an abortion were included in the online form.

For this study, we analysed online requests from Brazil received by Women Help Women between January 1, 2016 and June 30, 2017, capturing the time period after the start of the Zika epidemic through 
the end of the public health emergencies. We categorised the time period covered into four phases to characterise the Zika epidemic. These stages were informed by the declarations of public health emergencies by the Brazilian government and the WHO and included: (1) January 1, 2016 (after the start of the Brazilian declaration of a public health emergency) through the day before the declaration of the WHO PHEIC (January 31, 2016), (2) Declaration of the WHO PHEIC (February 1, 2016) to the end of the WHO PHEIC (November 18, 2016), (3) November 19, 2016 through the end of the Brazilian public health emergency (May 12, 2017), and (4) May 13, 2017-June 30, 2017.

Reasons for seeking an abortion were collected through a close-ended question. Requesters were asked to select all relevant reasons for their specific case. Possible responses were (1) not being prepared to have another child at that time, (2) considering their family complete, (3) not wanting children, (4) having financial problems, (5) facing housing issues, (6) having health problems, (7) feeling too young or too old to have children, (8) facing problems in their couple, (9) being single, (10) being unemployed, (11) having concerns about a child interfering with a job or career, (12) having concerns about a child interfering with education plans, (13) having concerns that the partner would not accept the pregnancy, (14) having concerns about family not accepting the pregnancy, (15) having a pregnancy that was a result of rape, (16) being afraid of Zika, (17) having a reason other than those listed, and (18) preferring not to share. If the requester indicated that they had another reason for seeking an abortion, they had the opportunity to enter text to describe the reason. We reviewed the reasons specified in the 'Other reason' field for any mention of Zika $(n=4)$, however all requesters that mentioned Zika in the open responses had already selected Zika in the close ended options. If a requester selected that they were concerned about Zika, they were prompted to answer three followup questions probing for more information about whether they had been formally diagnosed with Zika, whether they thought they might have had Zika but were not diagnosed, and whether they were concerned that they were at risk of Zika during the pregnancy. These options were not mutually exclusive. To analyse the reasons for seeking abortion, we combined reasons about future plans (reasons 11 and 12), reasons related to concerns from partners and family members (13 and 14), financial reasons (reasons 4, 5, and 10), and reasons related to not wanting children at this time or any time (reasons 1, 2, and 3). Reasons 6-9 and 15-18 were analysed individually.

We categorised states into five regions defined by the Instituto Brasileiro de Geografia e Estatistica of Brazil: North, Northeast, Central-West, Southeast and South (Instituto Brasileiro de Geografia e Estatística, 2018). Where the state could not be ascertained from the information included in the state field, we considered the state and region of residence to be unknown. We calculated the number of weeks since last menstrual period at the time of the request based on the number of days since the last menstrual period and grouped responses into the following categories: $\leq 4$ weeks, $>4$ weeks- $\leq 6$ weeks, $>6$-weeks- $\leq 8$ weeks, $>8-\leq 12$ weeks, and $>12$ weeks. We calculated age based on birth date provided and analysed it in five groups $(<18,18-24,25-29,30-34,35+)$. When the age of the person requesting medication support was 56 or older, or less than 9 , we considered age to be missing. Options for pregnancy confirmation methods were ultrasound, blood pregnancy test, urine pregnancy test, and no confirmation. Requests that listed more than one method were assigned to the most invasive test following the order of the methods listed above (from most to least invasive).

The dataset also included information on whether the person requesting support followed up with Women Help Women after the initial consultation and reported accessing medication. Follow up data was not analysed for this study and researchers did not have access to any personal identifiable information of the requesters.

\subsection{Analysis}

\subsubsection{Overall requests to Women Help Women during the study period}

We present the overall number of daily requests for medication abortion support over the study period. Requests were stratified by the region of Brazil in which the person resided, weeks since the last menstrual period at the time of contact, age, and method by which the current pregnancy was confirmed. 


\subsubsection{Characterising requests that listed Zika as a reason for seeking abortion}

We analysed the total number of requests and the percent of requests listing Zika as a reason for seeking abortion services. We examined total requests by day and as daily averages by month. To standardise the measure of the number of requests across geographies, we present the number of requests per 100,000 women between the ages of 15-49, representing an average rate per person day for a given month. ${ }^{1}$ With this measure we do not aim to represent the total abortion rate in a given geography, but to standardise the number of requests in relation to the size of the population for comparison purposes. The number of requests per 100,000 women reflects how the total number of requests, as well as the number of requests citing Zika as a reason, changed over time. We used population estimates from the 2010 census (Instituto Brasileiro de Geografia e Estatística, 2014).

We constructed mixed-effects logistic models to analyse whether the proportion of requests listing Zika as a reason for seeking an abortion varied by age, method of pregnancy confirmation, and weeks since last menstrual period. We included these variables because those at later gestational ages and those who had ultrasounds may have received additional information about the possibility of malformations related to Zika. Methods of pregnancy confirmation may also be indicative of socioeconomic status, as urine pregnancy tests may be cheaper and more accessible than a blood pregnancy test or an ultrasound (de Almeida Gomes et al., 2019). We included age to understand whether concern about Zika was more prevalent among certain age groups (Chiavegatto Filho \& Kawachi, 2015). We ran separate mixed-effects logistic models for each characteristic to evaluate whether there was an association between each characteristic and the probability that a request listed Zika as a reason for abortion seeking. In these models we include a random effect on each month-year. We consider a $p$ value of less than or equal to 0.05 as significant, however, we emphasise that these models are meant only to be associative and not causal.

\subsubsection{Contextualising Zika concern amongst other reasons for seeking abortion}

We calculated the monthly unweighted average of the daily percent of requests made for each of the possible reasons for seeking an abortion to understand how the prevalence of citing Zika as a reason for seeking abortion changed in relationship to all requests received by Women Help Women. We also compared the total requests by reason as a rate at the national level to understand how the overall frequency of reasons changed over the time period, comparing Zika to all other reasons listed.

We calculated the average number of reasons that each user provided for seeking an abortion and examined the mean number of reasons stratified by whether the user listed Zika as a reason for seeking an abortion. We calculated the percent of requests that listed Zika as the sole reason for seeking abortion services, considering all requests and those that chose Zika as a reason for seeking abortion in turn.

Women Help Women users consented for their anonymized data to be analysed for research purposes. Our study does not qualify as human subject research under Title 45 Part 46 of the United States Code of Federal Regulations and therefore approval from an ethical review board was not required.

\section{Results}

\subsection{Overall requests to Women Help Women during the study period}

20,609 requests from people reporting they lived in Brazil were received by Women Help Women from January 1, 2016 to June 30, 2017. Throughout the study period, the number of daily requests ranged from 13 to 70 (Figure 1). The daily number of requests appeared to be increasing over time, despite cyclical variation. From January 1, 2016 to the start of the WHO PHEIC, the service received 
951 requests for medication abortion support, or an average of 30.7 a day (Table 1). During period spanning the WHO PHEIC, Women Help Women received almost 10,500 requests for medication abortion, translating to an average of 35.9 requests per day. After the end of the WHO PHEIC, the daily average continued to increase, from 39.3 between the end of the WHO PHEIC and the end of the Brazil public health emergency to 46.6 requests per day in the time after Brazil ended its public health emergency. The percent of days with over 30 requests increased from $56.7 \%$ in June of 2016 to $96.7 \%$ in June of 2017.

Requests from the Southeast region of Brazil were the most frequent in each time period, followed by the South and Northeast regions. The proportion of total requests from these regions remained relatively constant throughout the periods defined by the Zika epidemic (Table 1). Throughout all time periods, approximately half of the requests came from those between the ages of 18 and 24 . In the period between January 1, 2016 and the start of the WHO PHEIC, 42\% of requesters reported that they did not remember when their last menstrual period started, $32 \%$ of requests were submitted by those whose last menstrual period started 6 weeks ago or less, $18 \%$ reported their last menstrual period started between six and eight weeks ago, and $8 \%$ reported their last menstrual period started more than 8 weeks before the time of the request. The distribution of time since last menstrual period across requests remained stable throughout the study period. Between $44 \%$ and $46 \%$ of pregnancies were confirmed with a urine pregnancy test while $11 \%$ to $13 \%$ were confirmed with an ultrasound with little change documented over the time periods included in this study.

\subsection{Characterising requests that listed Zika as a reason for seeking abortion}

During March of 2016, the first month with complete data on reasons for seeking medication abortion support, an average of $15.0 \%$ of requests listed concern about Zika as a reason for seeking an

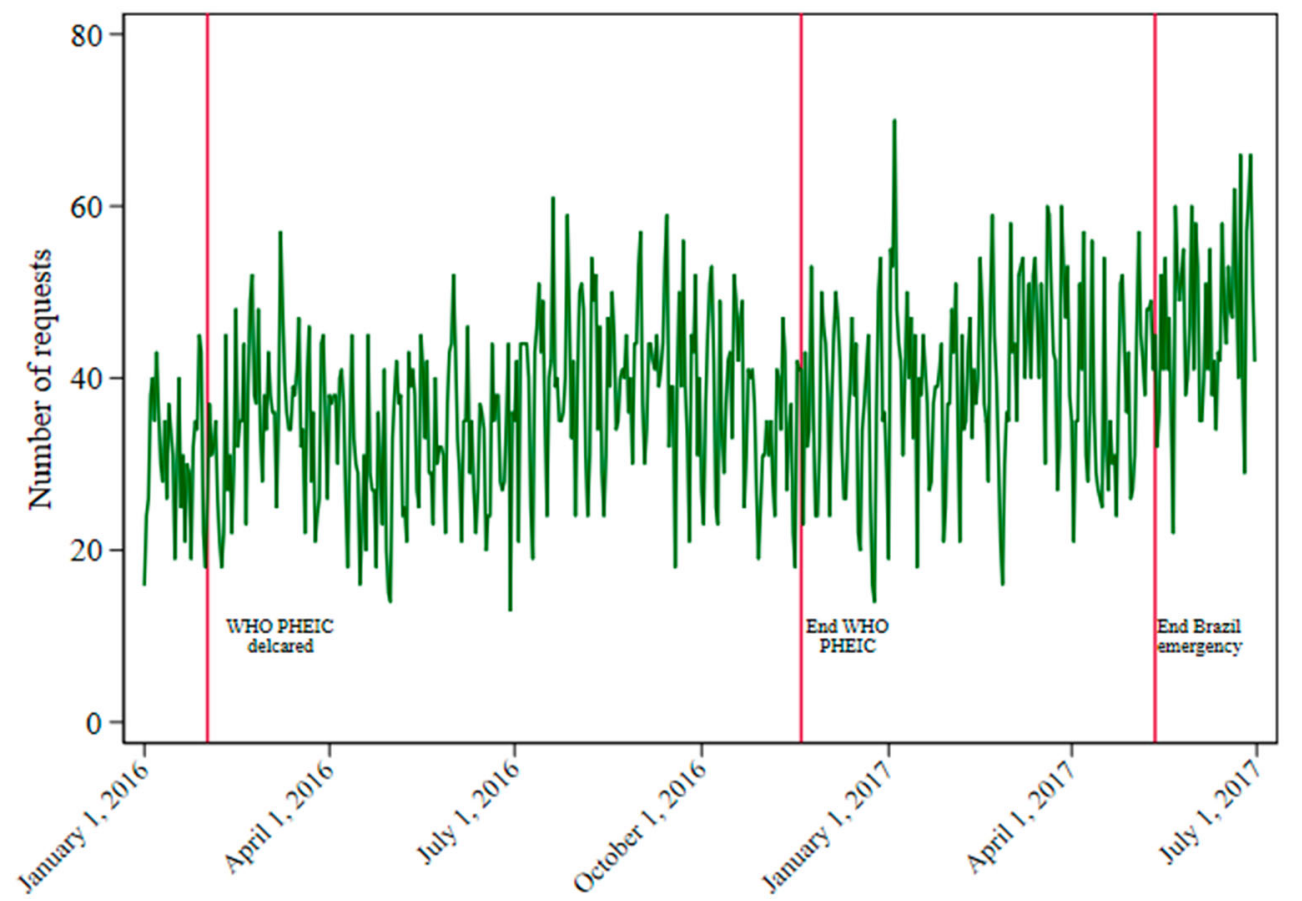

Figure 1. Requests for medication abortion support by day in Brazil: January 1, 2016- June 30, 2017. Caption: Graph represents the daily number of requests for medication abortion support received by Women Help Women over the course of the study period (January 1, 2016 to June 30, 2017). Important dates in the Zika virus epidemic are noted. Acronyms: Public Health Emergency of International Concern (PHEIC). 
Table 1. Characteristics of requests from Brazil for medication abortion support to Women Help Women.

\begin{tabular}{|c|c|c|c|c|c|c|c|c|c|c|}
\hline \multirow{2}{*}{$\mathrm{N}(\%)$} & \multicolumn{2}{|c|}{$\begin{array}{c}\text { January 1, } 2016 \text { - Start of } \\
\text { WHO PHEIC declaration }\end{array}$} & \multicolumn{2}{|c|}{$\begin{array}{c}\text { Start of WHO PHEIC - end of } \\
\text { WHO PHEIC }\end{array}$} & \multicolumn{2}{|c|}{$\begin{array}{c}\text { End of WHO PHEIC -end of } \\
\text { Brazil public health } \\
\text { emergency }\end{array}$} & \multicolumn{2}{|c|}{ After Brazil public health emergency } & \multicolumn{2}{|c|}{ Full time period } \\
\hline & $\begin{array}{l}\text { All requests } \\
(n=951)\end{array}$ & $\begin{array}{l}\text { Zika related } \\
(n=\mathrm{NA})^{*}\end{array}$ & $\begin{array}{l}\text { All-requests } \\
(n=10,494)\end{array}$ & $\begin{array}{l}\text { Zika related* } \\
\quad(n=793)\end{array}$ & $\begin{array}{l}\text { All requests } \\
(n=6,881)\end{array}$ & $\begin{array}{l}\text { Zika related } \\
(n=250)\end{array}$ & $\begin{array}{l}\text { All requests } \\
(n=2,283)\end{array}$ & Zika related $(n=40)$ & $\begin{array}{l}\text { All requests } \\
(n=20,609)\end{array}$ & $\begin{array}{l}\text { Zika related } \\
(n=1,083)\end{array}$ \\
\hline Request per day Mean (range) & $30.7(16-45)$ & - & $35.9(13-61)$ & $3.3(1-15)$ & $39.3(14-70)$ & $1.9(1-6)$ & $46.6(22-66)$ & $1.5(1-4)$ & $37.7(13-70)$ & $2.7(1-15)$ \\
\hline \multicolumn{11}{|l|}{ Region } \\
\hline North & 37 (3.9\%) & - & 395 (3.8\%) & 24 (3.0\%) & 285 (4.1\%) & 18 (7.2\%) & 74 (3.2\%) & 3 (7.5\%) & 791 (3.8\%) & 45 (4.2\%) \\
\hline Northeast & $122(12.8 \%)$ & - & $1236(11.8 \%)$ & $167(21.1 \%)$ & $857(12.5 \%)$ & $55(22.0 \%)$ & $276(12.1 \%)$ & $11(27.5 \%)$ & $2491(12.1 \%)$ & $233(21.5 \%)$ \\
\hline Central-West & $64(6.7 \%)$ & - & $971(9.3 \%)$ & $85(10.7 \%)$ & $583(8.5 \%)$ & $16(6.4 \%)$ & $201(8.8 \%)$ & $2(5.0 \%)$ & $1819(8.8 \%)$ & $103(9.5 \%)$ \\
\hline Southeast & $576(60.6 \%)$ & - & $5710(54.4 \%)$ & $408(51.5 \%)$ & $3942(57.3 \%)$ & $132(52.8 \%)$ & $1347(59.0 \%)$ & $16(40.0 \%)$ & $11575(56.2 \%)$ & $556(51.3 \%)$ \\
\hline South & $150(15.8 \%)$ & - & $1750(16.7 \%)$ & $82(10.3 \%)$ & $1148(16.7 \%)$ & $29(11.6 \%)$ & $356(15.6 \%)$ & 7 (17.5\%) & $3404(16.5 \%)$ & $118(10.9 \%)$ \\
\hline Unknown & $2(0.2 \%)$ & - & 432 (4.1\%) & $27(3.4 \%)$ & $66(1.0 \%)$ & $0(0.0 \%)$ & $29(1.3 \%)$ & $1(2.5 \%)$ & $529(2.6 \%)$ & $28(2.6 \%)$ \\
\hline \multicolumn{11}{|l|}{ Weeks since last menstrual period } \\
\hline$\leq 4$ weeks & $78(8.2 \%)$ & - & $1173(11.2 \%)$ & $100(12.6 \%)$ & $668(9.7 \%)$ & $22(8.8 \%)$ & $226(9.9 \%)$ & $3(7.5 \%)$ & $2145(10.4 \%)$ & $125(11.5 \%)$ \\
\hline$>4$ weeks- 6 weeks & $228(24.0 \%)$ & - & $2898(27.6 \%)$ & $248(31.3 \%)$ & $1901(27.6 \%)$ & $83(33.2 \%)$ & $635(27.8 \%)$ & $17(42.5 \%)$ & $5662(27.5 \%)$ & $348(32.1 \%)$ \\
\hline >6-weeks-8 weeks & $173(18.2 \%)$ & - & 1905 (18.2\%) & $152(19.2 \%)$ & 1425 (20.7\%) & $58(23.3 \%)$ & $472(20.7 \%)$ & $7(17.5 \%)$ & 3975 (19.3\%) & $217(20.0 \%)$ \\
\hline$>8-12$ weeks & $62(6.5 \%)$ & - & $867(8.3 \%)$ & $61(7.7 \%)$ & $628(9.1 \%)$ & $20(8.0 \%)$ & $193(8.5 \%)$ & $3(7.5 \%)$ & $1750(8.5 \%)$ & $84(7.8 \%)$ \\
\hline$>12$ weeks & 13 (1.4\%) & - & 137 (1.3\%) & $5(0.6 \%)$ & $96(1.4 \%)$ & $2(0.8 \%)$ & $33(1.4 \%)$ & $0(0.0 \%)$ & 279 (1.4\%) & $7(0.6 \%)$ \\
\hline Unknown & $397(41.7 \%)$ & - & $3514(33.5 \%)$ & $227(28.6 \%)$ & $2163(31.4 \%)$ & $65(26.0 \%)$ & $724(31.7 \%)$ & $10(25.0 \%)$ & $6798(33.0 \%)$ & $302(27.9 \%)$ \\
\hline \multicolumn{11}{|l|}{$A g e^{* *}$} \\
\hline$<18$ & $105(11.1 \%)$ & - & $1279(12.2 \%)$ & $59(7.5 \%)$ & 777 (11.3\%) & $18(7.2 \%)$ & 207 (9.1\%) & $7(17.5 \%)$ & $2368(11.5 \%)$ & $84(7.8 \%)$ \\
\hline $18-24$ & $470(49.5 \%)$ & - & $5443(51.9 \%)$ & $412(52.1 \%)$ & $3445(50.2 \%)$ & $120(48.2 \%)$ & $1158(50.9 \%)$ & $19(47.5 \%)$ & $10516(51.1 \%)$ & $551(51.0 \%)$ \\
\hline $25-29$ & $172(18.1 \%)$ & - & $1873(17.9 \%)$ & $151(19.1 \%)$ & 1309 (19.1\%) & $62(24.9 \%)$ & $450(19.8 \%)$ & $8(20.0 \%)$ & $3804(18.5 \%)$ & $221(20.5 \%)$ \\
\hline $30-34$ & $127(13.4 \%)$ & - & $1150(11.0 \%)$ & $108(13.7 \%)$ & 795 (11.6\%) & $21(8.4 \%)$ & $283(12.4 \%)$ & $5(12.5 \%)$ & $2355(11.4 \%)$ & $134(12.4 \%)$ \\
\hline $35+$ & $75(7.9 \%)$ & - & $736(7.0 \%)$ & $61(7.7 \%)$ & $534(7.8 \%)$ & $28(11.2 \%)$ & $179(7.9 \%)$ & $1(2.5 \%)$ & $1525(7.4 \%)$ & $90(8.3 \%)$ \\
\hline \multicolumn{11}{|l|}{ Method of confirming pregnancy† } \\
\hline Not listed & $52(5.5 \%)$ & - & $682(6.5 \%)$ & $48(6.1 \%)$ & $397(5.8 \%)$ & $12(4.8 \%)$ & $123(5.4 \%)$ & $6(15.0 \%)$ & $1254(6.1 \%)$ & $66(6.1 \%)$ \\
\hline Urine pregnancy test & $425(44.7 \%)$ & - & $4854(46.3 \%)$ & $329(41.5 \%)$ & $3187(46.3 \%)$ & $98(39.2 \%)$ & $1014(44.4 \%)$ & $15(37.5 \%)$ & $9480(46.0 \%)$ & $442(40.8 \%)$ \\
\hline Blood pregnancy test & $348(36.6 \%)$ & - & $3830(36.5 \%)$ & $324(40.9 \%)$ & $2460(35.8 \%)$ & $94(37.6 \%)$ & $849(37.2 \%)$ & $13(32.5 \%)$ & $7487(36.3 \%)$ & $431(39.8 \%)$ \\
\hline Ultrasound & $126(13.2 \%)$ & - & $1128(10.7 \%)$ & $92(11.6 \%)$ & $837(12.2 \%)$ & $46(18.4 \%)$ & $297(13.0 \%)$ & $6(15.0 \%)$ & $2388(11.6 \%)$ & $144(13.3 \%)$ \\
\hline
\end{tabular}

*Reasons for seeking abortion were introduced to the online form February 19, 2016

${ }^{* *}$ Age is missing for 41 requests.

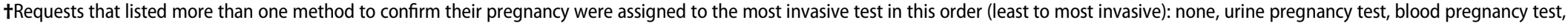
and ultrasound.

Acronyms: Public Health Emergency of International Concern (PHEIC). 
abortion. At the national level, the percent of requests that named Zika as a reason for seeking an abortion decreased over the time period; from an average of $7.9 \%$ of daily requests in June of 2016 to an average of $4.0 \%$ in December of 2016 and 1.5\% in June of 2017 (Figure 2a). Between the start of the WHO PHEIC to the end of the WHO PHEIC, Women Help Women received approximately 3.3 requests per day citing Zika as a reason for abortion seeking compared to 1.5 requests per day in the time period after the Brazil emergency ended (Table 1). The average daily rate of requests that listed concern about Zika as a reason for seeking an abortion also declined at the national level, decreasing from 0.01 average daily requests per 100,000 women aged 15-49 in March of 2016 to 0.0026 in December of 2016 and 0.0014 in June of 2017 (Figure 2b).

Among regions, the Northeast and Central-West regions had the highest percentage of requests that cited concern about Zika as a reason for seeking an abortion (Figure 3a). In March of 2016, the average daily percent of requests that listed Zika as a reason in these regions was $21.8 \%$ and $20.5 \%$ respectively. Fifteen percent of requests from the Southeast region cited concern about Zika as a reason in March of 2016. In these three regions there was a marked decline in the average percent of daily requests that listed Zika as a reason for seeking an abortion, mirroring the trend at the national level. The North region and the South region, with a lower proportion of Zika-related requests, had less marked declines in the percent of requests that listed Zika as a reason over the time period. By June of 2017, the average daily percent of requests that listed Zika as a reason for seeking an abortion was less than $5 \%$ in all regions. We observed sharp declines in the daily average rate of requests per 100,000 women aged 15-49 that listed concern about Zika as a reason for seeking an abortion in the Central-West and Southeast regions (Figure 3b). There appeared to be smaller declines in the Northeast and South regions, while the rates in the North region showed less of a trend.

Among those citing concern about Zika as a reason for seeking an abortion $(n=1083)$, most worried they were at risk of Zika during their pregnancy (80.5\%), while fewer reported having been diagnosed with Zika (12.7\%) or worrying that they had Zika but were not diagnosed (20.8\%). There was evidence from our mixed-effects logistic models that requesters under the age of 18 had lower odds of citing Zika as a reason for abortion seeking in comparison to all other age groups. Those who estimated more than 12 weeks from their last menstrual cycle were also less likely to report Zika as a concern compared to those who estimated it had been four weeks or less since the start of their last menstrual cycle at the time of request. Those who used an ultrasound or a blood pregnancy test to confirm their pregnancy were more likely to report Zika as a reason for abortion seeking

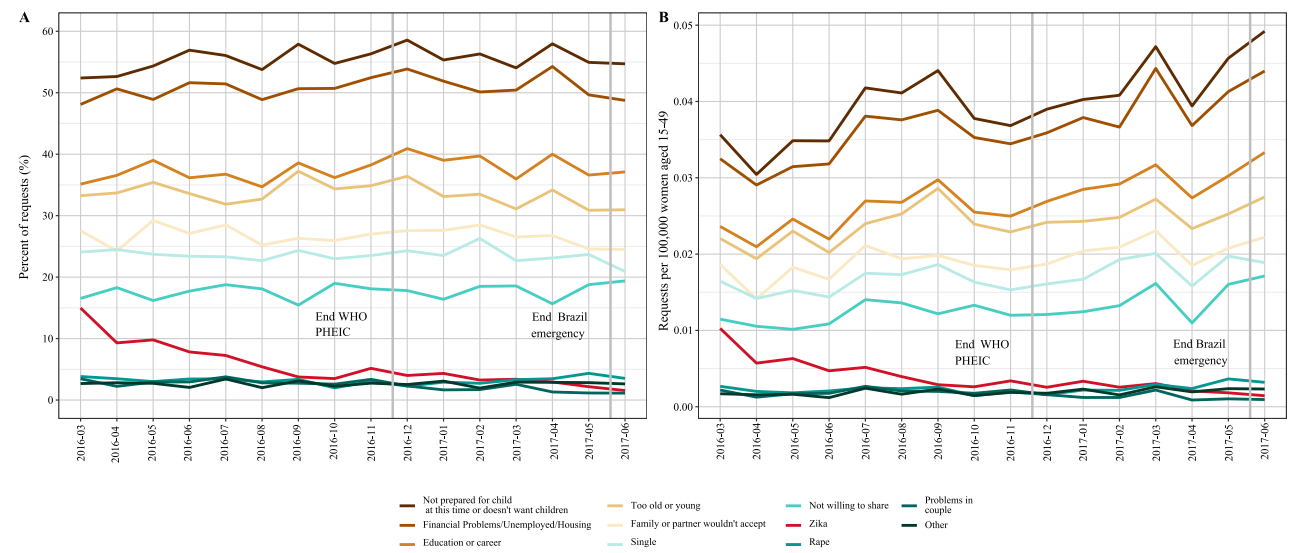

Figure 2 . (A) Average percent of daily requests by reason(s) listed for seeking abortion, by month (B) Average daily rate of requests by reason(s) listed for seeking abortion per 100,000 women aged 15-49, by month. Caption: Figure represents the average percent of daily requests and average daily rate of requests that list each pictured reason as a reason for seeking an abortion. These data are shown by month over the study period. Acronyms: Public Health Emergency of International Concern (PHEIC). 

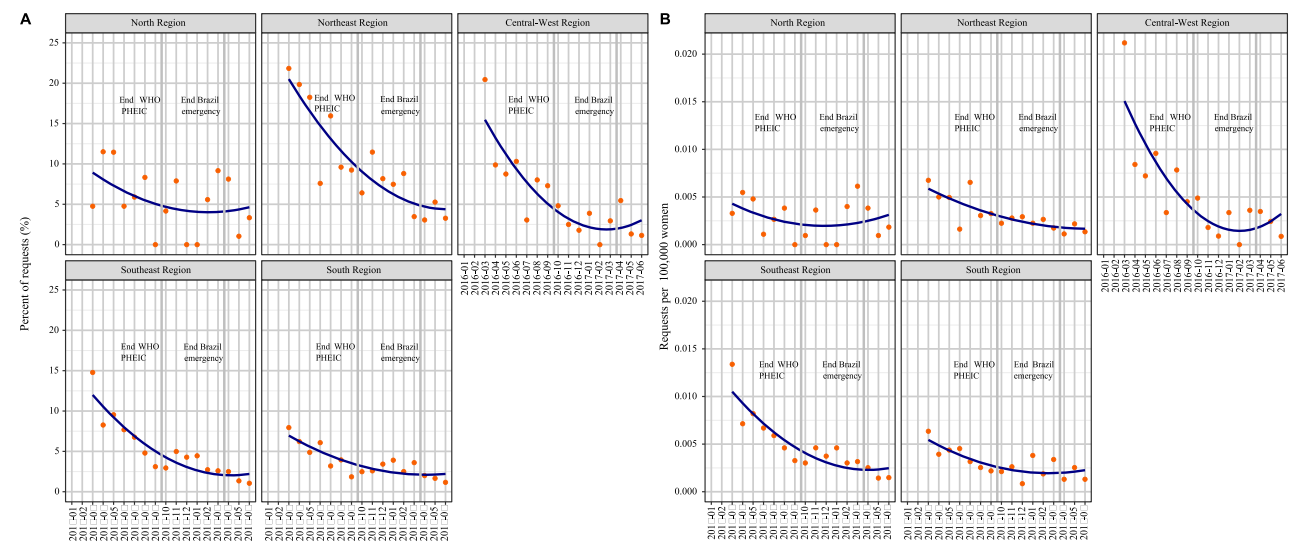

Figure 3. (A) Average percent of daily requests citing Zika as a reason for seeking an abortion as percent of total requests over time, by region (B) Requests citing Zika as a reason for seeking an abortion as average number of daily requests per 100,000 women aged 15-49 over time, by region. Caption: Points represent the average daily percent of requests citing concern about Zika as a reason for seeking an abortion and the average daily rate of requests citing concern about Zika as a reason for seeking an abortion per100,000 women aged 15-49 in each month. Blue lines represent a loess curve for the average daily percent of requests citing concern about Zika as a reason for seeking an abortion and the average daily rate of requests citing concern about Zika as a reason for seeking an abortion per100,000 women aged 15-49. Acronyms: Public Health Emergency of International Concern (PHEIC).

compared to those who used a urine pregnancy test to confirm their pregnancy. Descriptive statistics supporting these findings are shown in Table 1.

\subsection{Contextualising Zika concern amongst other reasons for seeking abortion}

Throughout the study period, the most common reason cited for seeking an abortion was not being prepared for a child at the time of the pregnancy or not wanting any or additional children (Figure $2 a)$. Between $52 \%$ and $59 \%$ of requesters cited these reasons. This was followed by financial reasons (financial problems, being unemployed, and housing). The average percent of daily requests listing each of the reasons not related to Zika stayed relatively constant during the study period, in contrast with the percent of requests listing Zika. Between $15 \%$ and $20 \%$ of requesters did not share a reason for requesting medication abortion support.

Examining the rate of requests, the most frequent reasons given for abortion seeking (not wanting children at this time or any time and financial reasons) increased over the time period (Figure $2 \mathrm{~b}$ ). The rate of requests noting Zika as a reason ranked eighth in overall frequency in March of 2016 during the height of the epidemic and declined to the second least frequent reason named in June of 2017.

Overall, 5.7\% of requests included Zika as a reason for seeking an abortion. Zika was listed as the only reason for seeking abortion services in $0.2 \%$ of cases overall and in less than $1 \%$ in every region. Those who named Zika as a reason for seeking an abortion named on average 4.5 additional reasons they were seeking an abortion in their request (a total of 5.5 reasons) compared to three reasons among those who did not name Zika. In 3.3\% of the requests including Zika as a reason for abortion seeking, Zika was the only reason listed. This percentage ranged from $0.0 \%$ in the South region to $6.7 \%$ in the North region.

\section{Discussion}

This study shows that the number of requests for medication abortion support received by Women Help Women increased over the study period, even after the Zika epidemic ended in Brazil. The distribution of requests by age, method of pregnancy diagnosis, region, and gestational age changed 
little over this period. Our results show that concern about Zika as a reason for seeking an abortion was highest during the peak of the Zika epidemic and declined as the epidemic slowed. This decline was reflected both in terms of the percentage of requesters that mentioned Zika as a reason for the abortion and in absolute numbers. Citing Zika as a reason for the abortion was more common in regions where incidence of Zika was highest. However, Zika was rarely the sole reason mentioned at any point during the study period and in any region. On the contrary, reasons related with personal decisions about parenting and financial situations were most commonly mentioned and this remained stable through different periods. These results suggest that alongside an unmet need for contraceptive services (Farias et al., 2016; Tavares et al., 2007), there is a large unmet need for abortion services in Brazil and that the decision to have an abortion in this context is linked to a wide range of reasons.

In our study, citing Zika as a reason for the abortion was more prevalent among those older than age 18 and among those who confirmed their pregnancy with a blood pregnancy test or ultrasound. We also found that mentioning Zika as a reason was less common among those who requested support at higher gestational ages. These results, though not causal, speak to the potential that there was differential concern about Zika among different groups of pregnant people in Brazil. It is possible that a lower prevalence of concern about Zika as a reason for the abortion among those under the age of 18 reflects the broader structures and constraints young people face when they get pregnant. This would make concern about Zika secondary to broader considerations such as educational factors, financial concerns, or readiness to have a child (Heilborn \& Cabral, 2011). The ways pregnancy diagnosis method and gestational age interact with Zika concern to influence decisions about seeking abortion deserve further exploration. Blood pregnancy tests and ultrasounds may be more common among people of higher socioeconomic status or with better access to health services. Additionally, an ultrasound may provide more information about the development of the fetus that would lead to a decision to seek abortion services. Blood pregnancy tests and ultrasounds may be more likely to take place at a health facility and lead to conversations with a provider about potential risks of Zika during pregnancy.

Although these results are descriptive, they point to a more nuanced picture than prior results have suggested about drivers of abortion in Brazil during and after the Zika epidemic (Aiken et al., 2016). Our results do suggest that Zika was part of the general consciousness of those requesting abortion, especially in areas where incidence of Zika was higher. Concern about Zika may have influenced abortion seeking overall; however, in large part, our study documents that need for abortion during and after the Zika epidemic was driven by factors outside of the concern caused by Zika. Even during the peak of the Zika epidemic when Zika factored more prominently into decisions to seek abortion services, concern about Zika often intersected with other reasons for seeking abortion. These results add to the mixed findings from prior research on changes in pregnancy intention, contraceptive purchasing, and contraceptive use in the context of Zika in Brazil (Bahamondes et al., 2017; Borges et al., 2018). Taken together, these results likely reflect the ongoing complexity of reproductive decision making even in the midst of a public health crisis (Center for Reproductive Rights, 2018).

Our results, although representing only a small percentage of the approximately 500,000 abortions that take place in Brazil annually, point to a large unmet need for abortion services that is being covered in part by online services like Women Help Women. These findings support the need for a broad conversation about access to comprehensive sexual and reproductive health services including abortion. Such conversations should acknowledge the need for abortion in relation to crises such as Zika, but also should recognise the need for abortion services in the broader context of people's lives. The August 2018 Supreme Court hearing on decriminalising abortion in Brazil was a step in this direction, emphasising the right to abortion services for all people regardless of socioeconomic position or reason for abortion seeking (Andreoni \& Londoño, 2018; Correa, 2018).

This study has several limitations. First, we utilised data collected from online consultations regardless of the outcome of the request. It is possible that these data include duplicate entries 
and potential errors in data entry into the online form. However, analysing a large dataset from people in need of abortion in a legally restricted context provides an invaluable opportunity for exploring the complexities of an understudied clandestine phenomenon. Second, given the fact that this is an online based service, requesters may be more likely to have access to internet and IT literacy than the general Brazilian population. Lower income and marginalised communities in Brazil were more likely to be affected by Zika (Castro et al., 2018; de Oliveira et al., 2017; de Souza et al., 2018), and may have had a harder time enacting changes in reproductive behaviour to respond to risks of Zika (Marteleto et al., 2017). This suggests that our sample may not include the population hardest hit by the Zika epidemic. These data are also not representative of abortion seeking across Brazil. Thus, the geographic pattern of our data cannot be generalised to be representative of abortion seeking in each region. It is likely that the number of requests in each region is more related to outreach strategies from the organisation than the need for abortion in each region. The time period included in this study began during the Zika epidemic. As such, we do not observe the rate of requests prior to the start of the epidemic. Finally, although we tried to control for the seasonal pattern of abortion in our analyses of differences in requests citing Zika as a concern by individual characteristics, these results should not be interpreted causally as additional temporal trends may still exist in our data and we have not controlled for potential confounders.

\section{Conclusion}

This study highlights that although concern about Zika was highest during the peak of the Zika epidemic, Zika was rarely the main reason for seeking an abortion at any point during the study period and often interacted with other reasons for seeking an abortion. These results show that the complexity of the abortion decision making process persists in the face of public health emergencies, drawing attention to the need for safe, accessible, quality abortion services. While the Zika epidemic increased visibility of lack of access to abortion services in Brazil, access to abortion must be understood in the broader context of people's lives and their reproductive choices.

\section{Note}

1. We acknowledge that not all people who are in need of abortion care and who submitted requests for medication abortion support identify as 'women'. However, the best approximation for the population who are able to become pregnant and may be in need of abortion care is women of reproductive age. Throughout this manuscript we use the gender-inclusive term 'people' where possible, and use the more specific 'women' when referring to the standardized rates we have created using the population of women 15-49.

\section{Acknowledgements}

We would like to thank Yasmin Reyes, MPH and Isabel Muñoz, MPH for their work processing and prepping data for this study. CG and KJ led the conceptualisation of the study; AW and CG led the design; AW lead the drafting of the manuscript; and SL, CG and KJ revised and edited the manuscript. All authors approved the final manuscript.

\section{Disclosure statement}

No potential conflict of interest was reported by the author(s).

\section{Data Availability Statement}

Due to our commitment to protect the confidentiality and anonymity of those requesting support from Women Help Women, we cannot make the data used for this study available for download. We are happy to answer any inquiries related to the data used for the manuscript and provide additional information, where possible. 


\section{References}

70,3\% dos domicílios do país têm saneamento adequado, aponta IBGE. Brasil. (2013, November 29). http://g1.globo. $\mathrm{com} /$ brasil/noticia/2013/11/703-dos-domicilios-do-pais-tem-saneamento-adequado-aponta-ibge.html.

Aiken, A. R. A., Digol, I., Trussell, J., \& Gomperts, R. (2017). Self reported outcomes and adverse events after medical abortion through online telemedicine: Population based study in the Republic of Ireland and Northern Ireland. BMJ, 357, j2011. https://doi.org/10.1136/bmj.j2011

Aiken, A. R. A., Scott, J. G., Gomperts, R., Trussell, J., Worrell, M., \& Aiken, C. E. (2016). Requests for abortion in Latin America related to concern about Zika virus exposure. New England Journal of Medicine, 375(4), 396-398. https:// doi.org/10.1056/NEJMc1605389

Albuquerque, M. V. D., Viana, A. L. D. Á., Lima, L. D. D., Ferreira, M. P., Fusaro, E. R., \& Iozzi, F. L. (2017). Regional health inequalities: Changes observed in Brazil from 2000-2016. Ciência \& Saúde Coletiva, 22(4), 1055-1064. https://doi.org/10.1590/1413-81232017224.26862016.

Ali, M., Miller, K., Folz, R., Johnson, B. R., \& Kiarie, J. (2017). Study protocol on establishment of sentinel sites network for contraceptive and abortion trends, needs and utilization of services in Zika virus affected countries. Reproductive Health, 14. https://doi.org/10.1186/s12978-017-0282-9

Andreoni, M., \& Londoño, E. (2018, August 4). Brazil's Supreme Court considers decriminalizing abortion. The New York Times. https:/www.nytimes.com/2018/08/03/world/americas/brazil-abortion-supreme-court.html.

Bahamondes, L., Ali, M., Monteiro, I., \& Fernandes, A. (2017). Contraceptive sales in the setting of the Zika virus epidemic. Human Reproduction (Oxford, England), 32(1), 88-93. https://doi.org/10.1093/humrep/dew310

Borges, A. L. V., Moreau, C., Burke, A., dos Santos, O. A., \& Chofakian, C. B. (2018). Women's reproductive health knowledge, attitudes and practices in relation to the Zika virus outbreak in northeast Brazil. PLoS ONE, 13, 1. https://doi.org/10.1371/journal.pone.0190024

Castro, M. C., Han, Q. C., Carvalho, L. R., Victora, C. G., \& França, G. V. A. (2018). Implications of Zika virus and congenital Zika syndrome for the number of live births in Brazil. Proceedings of the National Academy of Sciences, 201718476. https://doi.org/10.1073/pnas.1718476115

Center for Reproductive Rights. (2018). Unheard voices: Women's experiences wth Zika. https://www. reproductiverights.org/sites/crr.civicactions.net/files/documents/CRR-Zika-Brazil\%20(1).pdf.

Chiavegatto Filho, A. D. P., \& Kawachi, I. (2015). Income inequality is associated with adolescent fertility in Brazil: A longitudinal multilevel analysis of 5,565 municipalities. BMC Public Health, 15(1), 103. https://doi.org/10.1186/ s12889-015-1369-2

Correa, S. (2018). Brazilian supreme court public hearing on the decriminialization of abortion: Antecedents, contents, and effects. Sexual Policy Watch. https:/www.sxpolitics.org/wp-content/uploads/2018/09/Brazilian-SupremeCourt-Public-Hearing-on-the-Decriminalization-of-Abortion-2018.pdf.

de Almeida Gomes, M. N., de Oliveira Santos, L. K., De Matos, M. A. B., Lopes, P. R. R., de Veiga Chomatas, E. R., Barra, R. P., \& de Medeiros, E. B. (2019). Saude da mulher na gestacao parto e puerperio: Guia de orientacao para as secretarias estaduais e municipais de saude. Ministerio da saude, Patria Amada Brasil, Governo Federal. https://atencaobasica.saude.rs.gov.br/upload/arquivos/202001/03091259-nt-gestante-planificasus.pdf.

de Oliveira, W. K., de França, G. V. A., Carmo, E. H., Duncan, B. B., de Souza Kuchenbecker, R., \& Schmidt, M. I. (2017). Infection-related microcephaly after the 2015 and 2016 Zika virus outbreaks in Brazil: A surveillancebased analysis. The Lancet, 390(10097), 861-870. https://doi.org/10.1016/S0140-6736(17)31368-5

de Souza, W. V., Vazquez, E., Bezerra, L. C. A., Mendes, A. d. C. G., Lyra, T. M., de Araujo, T. V. B., de Oliveira, A. L. S., Braga, M. C., de Alencar Ximenes, R. A., \& de Barros Miranda-Filho, D. (2018). Microcephaly epidemic related to the Zika virus and living conditions in Recife, Northeast Brazil. BMC Public Health, 18(1), 130. https://doi.org/10. 1186/s12889-018-5039-Z

Diniz, D., \& Medeiros, M. (2010). [Abortion in Brazil: A household survey using the ballot box technique]. Ciencia \& Saude Coletiva, 15(Suppl 1), 959-966. https://doi.org/10.1590/S1413-81232010000700002

Diniz, D., Medeiros, M., \& Madeiro, A. (2017). National abortion survey 2016. Ciência \& Saúde Coletiva, 22(2), 653660. https://doi.org/10.1590/1413-81232017222.23812016

Farias, M. R., Leite, S. N., Tavares, N. U. L., Oliveira, M. A., Arrais, P. S. D., Bertoldi, A. D., Pizzol, T. d. S. D., Luiza, V. L., Ramos, L. R., \& Mengue, S. S. (2016). Use of and access to oral and injectable contraceptives in Brazil. Revista de Saúde Pública, 50(suppl 2). https://doi.org/10.1590/s1518-8787.2016050006176

Foster, A. M., Arnott, G., \& Hobstetter, M. (2017). Community-based distribution of misoprostol for early abortion: Evaluation of a program along the Thailand-Burma border. Contraception, 96(4), 242-247. https://doi.org/10.1016/ j.contraception.2017.06.006

Fusco, C. (2013). Unsafe abortion: A serious public health issue in a poverty stricken population. Reprodução \& Climatério, 28(1), 2-9. https://doi.org/10.1016/j.recli.2013.04.001

Fusco, C., Akerman, M., Drezett, J., \& de Souza e Silva, R. (2016). Social determinants of health: From the concept to the practice in outcomes of unintended pregnancies which result in induced abortion. Reprodução \& Climatério, 31 (1), 22-30. https://doi.org/10.1016/j.recli.2015.12.003 
Gerdts, C., Jayaweera, R. T., Baum, S. E., \& Hudaya, I. (2018). Second-trimester medication abortion outside the clinic setting: An analysis of electronic client records from a safe abortion hotline in Indonesia. BMJ Sex Reprod Health, 44 (4), 286-291. https://doi.org/10.1136/bmjsrh-2018-200102

Gomperts, R., Jelinska, K., Davies, S., Gemzell-Danielsson, K., \& Kleiverda, G. (2008). Using telemedicine for termination of pregnancy with mifepristone and misoprostol in settings where there is no access to safe services. BJOG: $A n$ International Journal of Obstetrics and Gynaecology, 115(9), 1171-1178. https://doi.org/10.1111/j.1471-0528.2008. 01787.x

Gomperts, R., van der Vleuten, K., Jelinska, K., da Costa, C. V., Gemzell-Danielsson, K., \& Kleiverda, G. (2014). Provision of medical abortion using telemedicine in Brazil. Contraception, 89(2), 129-133. https://doi.org/10. 1016/j.contraception.2013.11.005

Governo do Brasil. (2015, November 11). Governo aciona ações de emergência diante da alta de casos de microcefalia em PE. http://www.brasil.gov.br/noticias/saude/2015/11/governo-aciona-acoes-de-emergencia-diante-de-alta-decasos-de-microcefalia-em-pe.

Grossman, D., Baum, S. E., Andjelic, D., Tatum, C., Torres, G., Fuentes, L., \& Friedman, J. (2018). A harm-reduction model of abortion counseling about misoprostol use in Peru with telephone and in-person follow-up: A cohort study. PloS One, 13(1), e0189195. https://doi.org/10.1371/journal.pone.0189195

Heilborn, M. L., \& Cabral, C. S. (2011). A new look at teenage pregnancy in Brazil. ISRN Obstetrics and Gynecology, 2011, 1-7. https://doi.org/10.5402/2011/975234

Instituto Brasileiro de Geografia e Estatística. (2014). Censo Demografico 2010. https://biblioteca.ibge.gov.br/ visualizacao/periodicos/552/cd_2010_agsn_if.pdf.

Instituto Brasileiro de Geografia e Estatística. (2018). Divisão regional do Brasil em regiões geográficas imediatas e regiões geográficas intermediárias: 2017. https://biblioteca.ibge.gov.br/index.php/biblioteca-catalogo?view= detalhes\&id $=2100600$.

Kane, G., Galli, B., \& Skuster, P. (2013). When abortion is a crime: A threat to vulnerable women in Latin America. IPAS.

Marinho, F., Araújo, V. E. M. d., Porto, D. L., Ferreira, H. L., Coelho, M. R. S., Lecca, R. C. R., Oliveira, H. d., Poncioni, I. P. d. A., Maranhão, M. H. N., Mendes, Y. M. M. B. E., Fernandes, R. M., Lima, R. B. d., \& Rabello, D. d. L. (2016). Microcephaly in Brazil: Prevalence and characterization of cases from the information system on live births (sinasc), 2000-2015. Epidemiologia E Servicos De Saude: Revista Do Sistema Unico De Saude Do Brasil, 25(4), 701-712. https://doi.org/10.5123/S1679-49742016000400004

Marteleto, L. J., Weitzman, A., Coutinho, R. Z., \& Alves, S. V. (2017). Women's reproductive intentions and behaviors during the Zika epidemic in Brazil. Population and Development Review, 43(2), 199-227. https://doi.org/10.1111/ padr.12074

Ministério da Saúde. (2009). Pesquisa Nacional de Demografia e Saúde da Criança e da Mulher 1996 e 2006. http:// bvsms.saude.gov.br/bvs/publicacoes/pnds_crianca_mulher.pdf.

Ministério da Saúde. (2015). Protocolo de atenção à saúde e resposta à ocorrência de microcefalia relacionada à infecção pelo vírus Zika. Ministério da Saúde, Secretaria de Atenção à Saúde. Brasília.

Moseson, H., Herold, S., Filippa, S., Barr-Walker, J., \& Baum, S.E. (2020). Self-managed abortion: a systematic scoping review. Best Practice \& Research Clinical Obstetrics \& Gynaecology, 63, 87-110.

Paradella, R. (2018). North and Northeast have limited access to basic sanitation. IBGE - Agência de Notícias. Retrieved December 18, 2018, from https://agenciadenoticias.ibge.gov.br/en/agencia-news/2184-news-agency/news/20992north-and-northeast-have-limited-access-to-basic-sanitation

Tavares, L. S., Leite, I. d. C., \& Telles, F. S. P. (2007). Unmet contraception needs in Brazil. Revista Brasileira de Epidemiologia, 10(2), 139-148. https://doi.org/10.1590/S1415-790X2007000200002

Theme-Filha, M. M., Baldisserotto, M. L., Fraga, A. C. S. A., Ayers, S., Nogueira da Gama, S. G., \& do Carmo Leal, M. (2016). Factors associated with unintended pregnancy in Brazil: cross-sectional results from the Birth in Brazil National Survey, 2011/2012. Reproductive Health, 13(Suppl 3), 118. https://doi.org/10.1186/s12978-016-0227-8..

World Health Organization. (2007). Task shifting to tackle health worker shortages. http://www.who.int/healthsystems/ task_shifting_booklet.pdf.

World Health Organization. (2016, February 1). WHO Director-General summarizes the outcome of the Emergency Committee regarding clusters of microcephaly and Guillain-Barré syndrome. https://www.who.int/en/news-room/ detail/01-02-2016-who-director-general-summarizes-the-outcome-of-the-emergency-committee-regardingclusters-of-microcephaly-and-guillain-barr\%C3\%A9-syndrome. 